\title{
Dynamic Forecasting and the Demand for Money
}

\author{
SCOTT E. HEIN
}

M UCH of the statistical evidence on the breakdown in the short-run demand for money relationship in the United States results from poor dynamic outof-sample simulations over the post-1974 period. ${ }^{1}$ However, this evidence must be regarded cautiously because the dynamic forecasting procedure lacks a firm econometric foundation.

This paper reexamines the conclusions that have emerged from these inadequate dynamic money demand forecasts. First, it presents a conventional money demand relationship and its post-1974 dynamic forecasts, along with a restatement of the conclusions

1Since only ex post forecasting is discussed in this paper, the terms "forecasts" and "out-of-sample simulations" are used interchangeably. In addition, this paper discusses the stability of a relationship in the statistical sense: a relationship is said to be stable if the regression coefficients are statistically invariant with time.

The following studies rely heavily on dynamic forecasting performance in their analysis of the stability of the demand for money relationship: Stephen M. Goldfeld, "The Case of the Missing Money, Brookings Papers on Economic Activity (3;1976), pp. 683-730; Jared Enzler, Lewis Johnson, and joln Paulus, "Some Problems of Money Demand," Brookings Papers on Economic Acticity (1:1976), po. 261-79; Michael ]. Harmburger, "Behavior of the Money Stock: Is There a Puzzle?" Journal of Monetary Economics (No. 3, 1977), pp. 265-88,

Gitlian Garcia and Simon Pak "Some Clues in the Case of the Missing Money," American Economic Review, Papers and Proceedings (May 1979), pp. 330-34; and Richard D. Porter, Thomas D. Simpson, and Eileen Mauskopt, "Financial Innovation and the Monetary Aggregates," Brookings Papers on Economic Activity (1:1979), pp. 213-29.

\author{
ERRATA: Change $\ddot{y}$ to $\hat{y}$ in eq. $4 \& 11$; \\ p. 16 , col. 1, line 9 ; p. 16 , col. \\ 2, line 20. Change $\tilde{Y}_{T+2}{ }^{-Y_{T}}$ to \\ $\mathrm{Y}_{\mathrm{T}+2}-\overline{\mathrm{Y}}_{\mathrm{T}+2}$, p. 17, col. 2, line 2 .
}

drawn from such an investigation. ${ }^{2}$ Next, the dynamic forecasting procedure is contrasted, in general terms, with the more widely understood static forecasting technique. This analysis provides a framework for reevaluating conclusions about the breakdown in the money demand relationship.

The review demonstrates that certain inferences drawn from dynamic forecasts of money demand over the post-1974 period are incorrect and misleading. In general, the pattern and the degree of breakdown in the money demand relationship has been obscured by reliance on this forecasting procedure. The shifts are neither as large nor as frequent as suggested by the dynamic forecast errors.

\section{Convertional Demand for Money Relatonship and Is Dundwic Forecasts}

The money demand relationship considered here is given by:

$$
\text { (1) } \quad \ln \left(\begin{array}{c}
\left.\mathrm{M}_{\mathrm{t}} / \mathrm{P}_{\mathrm{t}}\right)=\alpha_{0}+\alpha_{\mathrm{t}} \ln \mathrm{TBR}_{\mathrm{t}}+\alpha_{2} \ln \mathrm{RCB} \\
+\alpha_{\mathrm{t}} \ln \mathrm{GNPR}_{\mathrm{t}}+\alpha_{\mathrm{t}} \ln \left(\mathrm{M}_{\mathrm{t}-1} / \mathrm{P}_{\mathrm{t}-\mathrm{t}}\right)+\varepsilon_{\mathrm{t}}
\end{array}\right.
$$

where $M$ is measured by old ML balances, $P$ is the

\footnotetext{
With the exception of Michael J. Hamburger and Gillian Garcia and Simon Pak, all of the above studies obtained poor ont-of-sample money demand simulations for the post-1974 period. For an alternative view on the stability suggested by Hamburger and Garcia-Pak, see $R$. W. Hafer and Scott E. Hein, "Evidence on the Temporal Stability of the Demand for Money Relationship in the United States," this Review (December 1979), pp. 3-14.
} 
implicit GNP deflator $(1972=100)$, TBR is the treasury bill rate, RCB is the commercial bank passbook rate, GNPR is real GNP ( 1972 dollars), and $\varepsilon_{t}$ is a random error term. ${ }^{3}$ This relationship was estimated for the sample period IV/1960 - II/1974 with ordinary least squares, after correcting for serial correlation in the error terms. ${ }^{4}$ The estimated coefficients and summary statistics are as follows: ${ }^{5}$

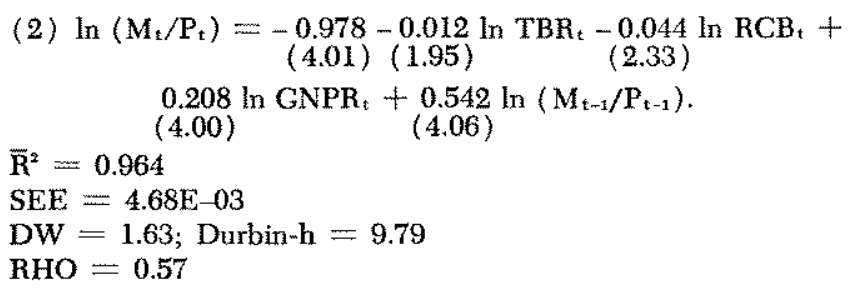

All estimated coefficients have the anticipated sign, are significantly different from zero, and are similar in magnitude to those found by others. The coefficient of determination corrected for degrees of freedom, $\overline{\mathrm{R}}^{2}$, shows that a substantial portion of the variation in real money balances is explained by the independent variables on the right-hand side of the equation.

This estimated equation was used to dynamically forecast the dependent variable, $\ln \left(\mathrm{M}_{\mathrm{t}} / \mathrm{P}_{\mathrm{t}}\right)$, for the post-sample period III/1974 - IV/1979. With the exception of the lagged dependent variable, actual values of the independent variables were used to perform this dynamic simulation. For the first forecast, III/ 1974 , the actual value of the lagged dependent variable was used; thereafter, the previous period's forecast for this variable was utilized. The dynamic money

3This relationship and sample period were chosen for comparison purposes. The relationship is similar to money demand specifications estimated by Goldfeld and Porter, et. al. Both studies, however, deflate the lagged money term on the righthand side of the equation by the contemporaneous price level. In this study, the lagged money term is deflated by the lagged price level so that the relationship has a true lagged dependent variable. This simplifies the procedure used to obtain dynamic forecasts. The sample period used in the study coincides with that investigated by Porter, et. al.

4This author, in a paper co-authored with R. W. Hafer, "The Dynamics and Estimation of Short-Run Money Demand," this Review (March 1980), pp. 26-35, argnes that directly estimating the relationship deseribed in equation (1) will yield inconsistent estimates; the relationship should be firstdifferenced before estimation. When this estimation procedure is employed, the supposed breakdown in the relationship is no longer evident. This present paper, however, follows the more widely accepted practice of estimating equation (1) directly, with the Cochrane-Orcutt techmique.

"The Durbin-h statistic, which is appropriate to test for serial correlation in the disturbances when a lagged dependent variable is present, indicates the existence of first-order autocorrelation, even after the Cochrane-Orcutt technique is used. This is a serious problem, indicating that more attention should be devoted to the actual estimation technique employed. However, since this specification and estimation technique is widely used in money demand studies, no attempt to correct this problem is made here. It should be noted that the estimation results reported by Porter, et. al, are subject to the same criticism. demand forecasts and resulting forecast errors presented in table 1 (columns 3 and 4, respectively) are in general agreement with those found by others.

Real money balances are consistently overpredicted and by increasing proportions (table 1, column 6). For example, by the second quarter of 1978 , prior to the introduction of nationwide ATS accounts and New York NOW accounts, real money balances were forecasted to be approximately $\$ 27$ billion above the actual level for that period. ${ }^{\text {. }}$

The inability to accurately simulate the movement of real money balances over this period led to the general conclusion that the money demand relationship shifted. In reviewing the evidence, Kimball states: "As these overpredictions continued and increased in size through 1975 and 1976, many economists concluded that the money demand function had shifted during 1974 by a substantial amount and that this shift placed in doubt the usefulness of (old) M1 as either an indicator of GNP or as a policy instrument."'

This summary statement pinpoints three separate conclusions drawn from the errors associated with dy. namic out-of-sample simulations of money demand. First, there is the contention that the relationship was subject to some sort of shift in or around 1974. The forecast errors suggest that this shift was quite sizable. Second, the dynamic forecasting errors suggest that the relationship has been shifting ever since late 1974 (column 3 , table 1). This view is consistent with the notion of a negative drift in money demand over the period. ${ }^{8}$ Finally, the evidence of a shift and subsequent drift has raised a question about the usefulness of this money measure as an indicator of monetary policy.

\section{Static Versus Dynamic Forecasts: A General Compar'son}

Although the dynamic forecasting procedure has been a primary tool used to evaluate the statistical breakdown in the money demand relationship, it has received little, if any, attention in the econometric literature. This section attempts to partially fill the

\footnotetext{
"It is felt that the introduction of these interest-bearing "check" ing deposits" has led to a shift out of conventional demand deposits. Evidence of this type of shift is provided subsequently. TRaph C. Kimball, "Wire Transfer and the Demand for Money," Federal Reserve Bank of Boston New England Economic Review (March/April 1980), p. 14.

"See for example, Porter, et al., "Financial Innovations and the Monetary Aggregates," p. 214. In that article, table 1 indicates that quaterly real balances grew at an amntalized rate of nearly 4 percent below that siggested by the estimation equation for the period III/1974-1V/1976. Also, see "Inflation and the Destruction of Monetarisna," (New York: Coldman Sachs Economics, November 1979), pp. 5-12.
} 


\section{Table 1}

\begin{tabular}{|c|c|c|c|c|c|}
\hline Date & $\ln (\mathrm{Actual} / \mathrm{P})$ & $\begin{array}{l}\text { Dynamic } \\
\text { forecast of } \\
\ln (\mathrm{M} / \mathrm{P})\end{array}$ & $\begin{array}{l}\text { Dynamic } \\
\text { torecast } \\
\text { error }\end{array}$ & $\begin{array}{l}\text { Dynamic torecast } \\
\text { error as } \\
\text { percent of } \\
\text { dependent vartable }\end{array}$ & $\begin{array}{l}\text { Dynamic torecast } \\
\text { error in billions } \\
\text { of real } \\
\text { money balances }\end{array}$ \\
\hline $11 / 1974$ & 0.8645 & 0.8865 & $-0,0220$ & -2.54 & $\$-5,28$ \\
\hline V/1974 & 0.8462 & 0.8872 & -0.0410 & -4.84 & -9.75 \\
\hline $1 / 1975$ & 0.8260 & 0.8851 & 0.0591 & -7.16 & $-13,91$ \\
\hline $1 / 1975$ & 0.8260 & 0.8880 & -0.0620 & -7.51 & $-14,61$ \\
\hline $11 / 1975$ & 0.8264 & 0.8925 & -0.0661 & 8.00 & -1561 \\
\hline W/1975 & 0.8187 & 0,8975 & 0.0780 & 9.63 & -18.59 \\
\hline $1 / 1976$ & 0.8213 & 0.9071 & 0,0858 & -10.44 & 20,37 \\
\hline $11 / 1976$ & 0.8258 & 0.9129 & 0.0871 & 10.55 & 20.78 \\
\hline $111 / 1976$ & 0.8246 & 0.9178 & 0.0932 & $-11,31$ & $-22,28$ \\
\hline V/1976 & 0.8283 & 0.9233 & 0.0950 & -11.47 & -22.82 \\
\hline $1 / 1977$ & 0,8320 & 0,9310 & 0.0990 & -11.90 & -23.91 \\
\hline $11 / 1977$ & 0.8319 & 0.9371 & 0,1052 & -12.65 & -25.49 \\
\hline $111 / 1977$ & 0.8415 & 0,9425 & 01009 & $-11,99$ & $-24,65$ \\
\hline IV/1977. & 0.8442 & 0.9452 & 0.1010 & 11,96 & $-24,72$ \\
\hline V/1978 & 0.8455 & 0,9470 & $-0,1015$ & -1200 & -24.88 \\
\hline $11 / 1978$ & 0.8429 & 09519 & 0,1000 & -1293 & -26.75 \\
\hline $111 / 1978$ & 0.8451 & 0.9549 & $-0,1098$ & -1299 & -2702 \\
\hline N/1978 & 0.8350 & 0.9574 & 0,1224 & -14.66 & $-30,01$ \\
\hline $1 / 1979$ & 0.8092 & 0,9584 & 0,1492 & 48,44 & $-36,14$ \\
\hline $1 / / 1979$ & 0,8071 & 0.9619 & 0,1548 & $-19,18$ & $-37,52$ \\
\hline $111 / 1979$ & 0,8107 & 0,9591 & 01484 & -18.31 & 35,99 \\
\hline IV/ 1979 & 0,8032 & 0.9550 & 0.1519 & $-18,91$ & $-36,60$ \\
\hline
\end{tabular}

\begin{tabular}{|c|c|}
\hline \multicolumn{2}{|c|}{ Summary statistics. } \\
\hline \multicolumn{2}{|l|}{ Mean error: } \\
\hline Root-mean-squared-error: & 0.103 \\
\hline Thell's inequality coetficient: & 0.124 \\
\hline \multicolumn{2}{|l|}{ Fraction of error due to } \\
\hline (A) Blas: & 0.890 \\
\hline (B) Varlation: & 0.015 \\
\hline (C) Co-variation: & 0.095 \\
\hline
\end{tabular}

Calculated as actual real money stock, less the exponenttal of the predicted logarthm of real money balances.

void by focusing on dynamic forecasting as a basis for evaluating the temporal stability (i.e., the constancy of the coefficients) of an economie relationship.

To facilitate understanding, the static forecasting procedure is discussed first. Consider a general relationship in which the lagged dependent variable, as well as an additional explanatory variable, $\mathrm{X}$, are hypothesized to influence the contemporaneous value of the dependent variable. Specifically, assume that

(3) $Y_{t}=\alpha_{t}+\alpha_{1} X_{t}+\alpha_{2} Y_{t-1}+\varepsilon_{t}$

is the "true" model for $t=1,2, \ldots, T$. In this equation, $X$ is a non-stochastic independent variable, $\varepsilon_{t}$ are independent and identically normally distributed random variables with mean zero and variance $\sigma^{2}$, and 
the parameters $\alpha_{0}, \alpha_{1}, \alpha_{2}$ are non-stochastic and known with certainty."

Under these conditions the traditional static forecast for $\mathrm{Y}_{\mathrm{T}_{+}}$, conditioned on knowledge of $\mathrm{X}_{\mathrm{T}_{+1}}$ and $Y_{w^{\prime},}$, is

(4) $\tilde{\mathrm{Y}}_{\mathrm{T}+1}=\alpha_{0}+\alpha_{1} \mathrm{X}_{\mathrm{T}+1}+\alpha_{2} \mathrm{Y}_{\mathrm{T}}$.

According to the maintained hypothesis of structural stability, equation (3) is appropriate for period $\mathrm{T}+1$. As a result, a forecast error $\left(\mathrm{Y}_{\mathrm{T}+\mathrm{F}}-\overline{\mathrm{Y}}_{\mathrm{T}+1}\right)$ is expected and this error is equal to $\varepsilon_{\mathrm{T}^{\prime}+1}$. The expected value of the forecast error, $E\left(\varepsilon_{\mathrm{T}_{+1}}\right)$, is zero by assumption. It is important to recognize that this result can be gen eralized for any time period for which equation (3) is valid and a static forecast is developed. Specifically, for any time period for which equation (3) is true, a forecast error can be expected and this error will be a rardom variable with a zero expected value and a constant variance, $\sigma^{2}$ (table 2 ).

Provided the variance of the disturbances $\left(\sigma^{2}\right)$ is known, the static forecast errors can be used to determine whether the relationship is temporally stable (i.e., whether equation (3) holds atter T). The static forecast error should, by hypothesis, behave as a nor. mally distributed randon variable with mean zero and variance $\sigma^{2}$. Contradictory evidence, such as static forecast enors that are large relative to $\sigma^{2}$, would suggest that equation (3) does not characterize the post-sample period. Conststently one-sided static forecast errors (e.g., under- or overpredictions) would also support such a conclusion. Using similar reasoning, Brown, Durbin, and Evans have developed formal tests to ascertain whether a relationship such as that described by equation (3) remains valid over an extended time period. ${ }^{10}$

The difference between these static forecasts and the dynamic forecasts used in money demand studies is

\footnotetext{
The assumption that the patameters are known with certainty makes the analysis simpler and, nore importantly, doesn't eftect the central conclusions drawn in this section. The reader is refemed to Henri Theil. Applied Economic Fonecasting (Chicago, North-Holland, 1966), pp. 5-8, for a discussion of the case where the paraneters in (3) are ordinary least square estimates. The analysis in this paper, based on the assumption that the paraneters are known with certainty, will underestimate the varance of the forecast error if the forecasts are actually based on parameters that are obtamed from ordinary least squares.

10) L. Brown, J. Durbin, and J. M. Evans, "Techniques for Testing the Constancy of Regression Relationships Over Time, Jotrnal of the Royal Statistical Society (vol. 37 1975), pu. 149-92. In one sense, the test the authors describe is none general than that discussed here. Specifically, they investigate the stability of a relationship when the right-hand side pamaneters are actually random variables, and when $\sigma^{2}$ is monkown. However, they do not comsider the specific case in which a lagged dependent variable is in cluded as an additional explanatory variable.
}

simple and relatively straightforward; dynamic forecasts use previously forecasted values of the lagged dependent variable instead of actual values. In other words, the forecaster is assumed to know the actual value of all the explanatory variables on the righthand side of the equation, except for the lagged dependent variable. ${ }^{11}$ Consequently, in dynamic forecasting, an estimate of the lagged dependent variable - specifically, the value forecasted for the previous period - must replace the actual value of the variable that would be used in static forecasting. In this respect, the dynamic forecasts are developed as part of a recursive system.

To better understand the dynamic forecasting procedure, assume equation (3) holds for $t=1, \ldots T$, and dynamic forecasts for periods beyond $\mathrm{T}$ are desired. ${ }^{12}$ The actual value of $\mathrm{Y}_{\mathrm{T}}$ is used to form the initial dynamic forecast of $\mathrm{Y}_{\mathrm{T}+\mathrm{1}}$. Thus, the dynamic forecast for $T+1, \hat{\mathrm{Y}}_{\mathrm{T}+1}$, is equal to the static forecast, $\tilde{\mathrm{Y}}_{\mathrm{T}_{+1}}$ :

(5) $\tilde{Y}_{T+1}=\alpha_{0}+\alpha_{1} X_{T+1}+\alpha_{2} Y_{T}$.

The resulting dynamic forecast error $\left(\mathrm{Y}_{\mathrm{T}_{+1}}-\tilde{\mathrm{Y}}_{\mathrm{T}_{+3}}\right)$ is $\varepsilon_{T_{* 1}}$-identical to the forecast error that occurred in the static forecasting procedure. Consequently, everything said about the first static forecast error holds for the dynamic forecast error as well.

However, in forecasting $\mathrm{Y}$ for the subsequent period $(T+2)$, the forecasted value of $Y_{\mathrm{T}_{\mathrm{T}}+1}$, rather than the actual value, is used to develop the dynamic forecast. Thus, the $T+2$ dynamic forecast is represented by:

(6) $\overline{\mathrm{Y}}_{\mathrm{T}+2}=\alpha_{\mathrm{u}}+\alpha_{1} \mathrm{X}_{\mathrm{T}: 2}+\alpha_{2} \tilde{\mathrm{Y}}_{\mathrm{T}: \mathrm{I}}$

Using the equation for the previous period's dynamic forecast error,

(7) $\left.Y_{T_{12}}-\tilde{Y}_{T_{-1}}=\varepsilon_{T_{+1}} \quad \Leftrightarrow \tilde{Y}_{T_{11}}=Y_{T_{12}-\varepsilon_{T_{*} 1}}\right)$.

equation (6) can be rewritten as:

(8) $\hat{\mathrm{Y}}_{\mathrm{T}-2}=\alpha_{9}+\alpha_{1} \mathrm{X}_{\mathrm{T}, 2}+\alpha_{2}\left(\mathrm{Y}_{\mathrm{T}+1} \sim \varepsilon_{\mathrm{T}-1}\right)$.

1' Dynamic forecasting appears to be particularly appropriate for studying an equation that has a lagoed dependent variable and that is pat of a larger model. If the right-hand side tariables, other than the lagged dependent variable, vere all exogenous, dvmamic forecastimg would give a valid indication of the "sturiness" of that relationship. However, in the case of meney demand, all of the right-hand ride variables would be endogemons in a fuller modet and thus should be forecasted as well. In this respect, it is strange that dymanic forecasting has becme so poptalar in money demand studies, while trite ex ante forecasting (in which all of the right hand side rariables are forecasted would pro* vide better insight into the problems associated with actually foreasting money demand. Ex ante forecast errors womla provide a better inderstanding of the actual problems facing policymaters in forecasting the demand for momer.

12Recal the assumption that the parameters $\alpha_{1}, \alpha_{1}$, and $\alpha_{2}$ are assumed to be known with certainty. 


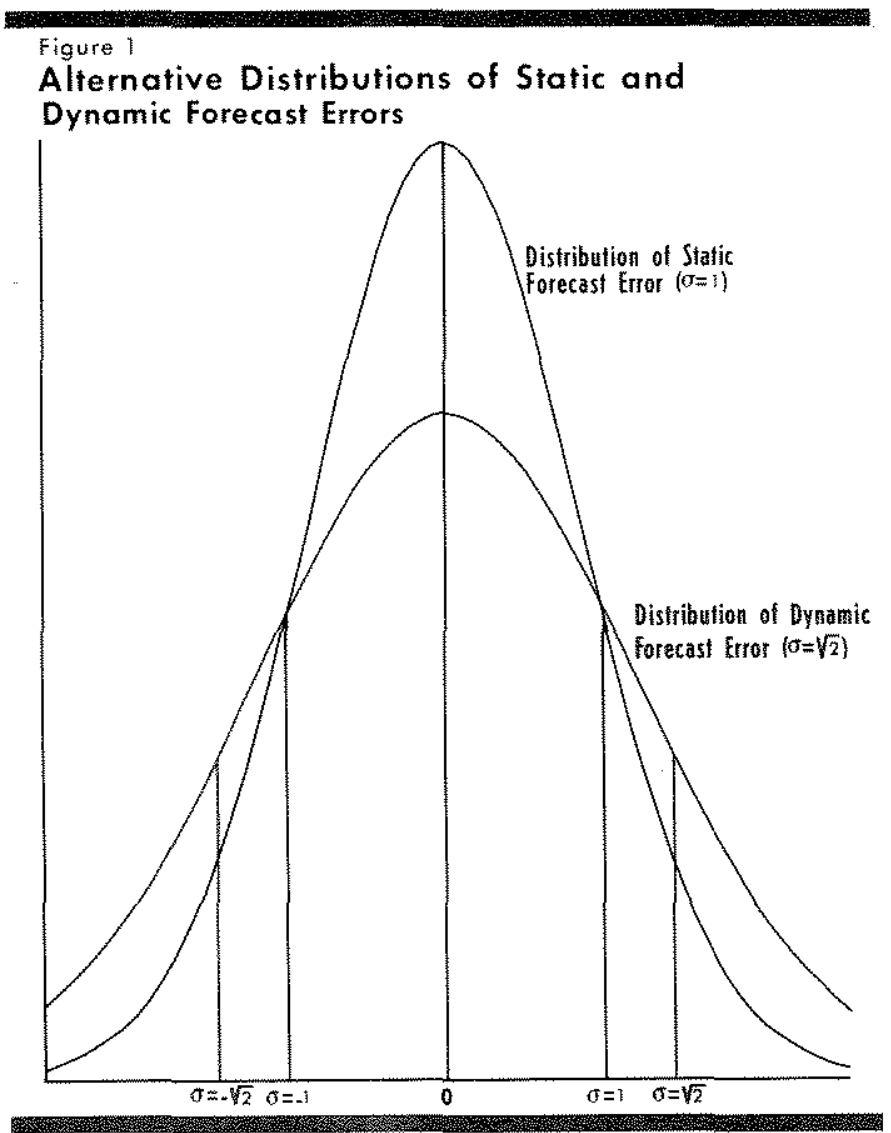

If equation (3) continues to hold for $\mathrm{T}+2$, the actual value of the dependent variable will be given by

(9) $\mathrm{Y}_{\mathrm{T}_{+3}}=\alpha_{0}+\alpha_{1} \mathrm{X}_{\mathrm{T}_{+2}}+\alpha_{2} \mathrm{Y}_{T+1}+\varepsilon_{\mathrm{T}+2}$.

Subtracting equation (8) from equation (9) yields the following dynamic forecast error for $\mathrm{T}+2$ :

(10) $\mathrm{Y}_{\mathrm{T}_{+2}}-\tilde{\mathrm{Y}}_{\mathrm{T}_{* 2}}=\varepsilon_{\mathrm{T}+2}+\alpha_{2} \varepsilon_{\mathrm{T}+1}$

which can be compared with the static forecast error for the same period:

(11) $\mathrm{Y}_{\mathrm{T}+2}-\overline{\mathrm{Y}}_{\mathrm{T}+2}=\varepsilon_{\mathrm{T}+2}$.

These alternative forecast errors are statistically similar in one sense, but quite different in another. Since, according to the null hypothesis of stability, the expected value of each disturbance, $\varepsilon_{\mathrm{t}}(t=1, \ldots)$, is zero, the expected value of both the static forecast error and the dynamic forecast error will be zero. In this respect, there would be no reason to prefer one forecasting procedure over the other, since both will yield unbiased forecasts.

The variance of these two forecast errors, however, is quite different. The variance of the static forecast error is the variance of the error, $\varepsilon_{\mathrm{T}+2}$, which is simply $\sigma^{2}$. Equation (10) shows that the variance of the dynamic forecast error will be larger than this for all cases in which $\alpha_{2}$ is non-zero. If the errors are independent, as has been assumed, the variance of the dynamic forecast error, $\operatorname{var}\left(\tilde{\mathrm{Y}}_{\mathrm{r}, 2}-\mathrm{Y}_{\mathrm{T}, 2}\right)$, is $\sigma^{2}\left[1+\alpha_{2}\right]^{2} \cdot^{13}$

Figure 1 compares the two altemative distributions under the assumption that both $\alpha_{2}$ and $\sigma_{z}$ equal unity. The distribution associated with the static forecast error is clearly more concentrated about the mean of the distribution than the dynamic forecast error. Since the standard deviation of the static forecast error is equal to one, it is smaller than the dynamic forecast error, which is equal to $\sqrt{2} \quad(\approx 1.414)$. In the statistical sense, the dynamic forecasting procedure can be considered inefficient relative to the static forecasting framework. This means that there is a higher probability of observing a dynamic forecasting error on the far tail ends of the distribution than there is with a static forecast. As a result, the investigator should be less confident in the former type of forecast.

In terms of evaluating the temporal stability of a relationship such as that presented in equation (3), the relatively larger variance associated with the dy-

13The variance of the dynamic forecast error, $\operatorname{Var}\left(\mathrm{Y}_{\mathrm{T}_{\mathrm{i}-2}-} \tilde{\mathrm{Y}}_{\mathrm{T}^{+2}+2}\right)$, equals $\operatorname{Var}\left(\varepsilon_{\mathbf{T}+2}+\alpha_{i} \varepsilon_{T_{+1}}\right)$ according to equation (10). This latter term, by assumption of independence in the disturbances, equals $\operatorname{Var}\left(\varepsilon_{T+2}\right)+\operatorname{Var}\left(\alpha_{*} \varepsilon_{\boldsymbol{T}+1}\right)$, which finally equals $\sigma^{2}+\alpha^{2} \sigma^{2}$. 


\begin{tabular}{|c|c|c|c|c|}
\hline Time & $\begin{array}{l}\text { Static } \\
\text { forecast } \\
\text { error }\end{array}$ & $\begin{array}{l}\text { Variance of } \\
\text { stafic } \\
\text { forecasterror }\end{array}$ & $\begin{array}{l}\text { Dynanic } \\
\text { forecast } \\
\text { error }\end{array}$ & $\begin{array}{l}\text { Variance of } \\
\text { dynamie } \\
\text { forecast entor }\end{array}$ \\
\hline$T+1$ & $\varepsilon_{n+1}$ & $\sigma$ & $\varepsilon_{\text {T+t }}$ & $\sigma^{2}$ \\
\hline $\mathrm{T}+2$ & $\varepsilon_{z+2}$ & o & $\varepsilon_{2+2}+\alpha_{2} \varepsilon_{n+1}$ & $\sigma^{\prime}(1+\alpha)$ \\
\hline $\mathrm{T}+3$ & $\varepsilon_{+4}$ & $\sigma^{\prime}$ & $\varepsilon_{r+3}+\alpha_{B} \varepsilon_{T+2}+\alpha_{2} \varepsilon_{r+1}$ & $\alpha^{3}\left(1+\alpha_{4}+\alpha_{4}\right.$ \\
\hline $\mathrm{T}+\mathrm{K}$ & $E_{7 \rightarrow R}$ & $\sigma^{3}$ & $\sum_{\Sigma=1}^{\mathbf{K}} \alpha_{2}^{(t-1)} \varepsilon_{T+8-(t-1)}$ & $\sigma^{\prime}\left[\sum_{i=0}^{k} \alpha_{i}{ }^{n}\right]$ \\
\hline
\end{tabular}

namic forecasting procedure indicates that, for any given confidence interval, a larger dynamic forecasting error (than that associated with the static forecasting procedure) is required before the null hypothesis of temporal stability can be rejected.

Table 2 presents static and dynamic forecast errors and the variance of these respective errors for periods $\mathrm{T}+1$ through $\mathrm{T}+3$. In addition, these particulars are generalized for the $K_{\text {th }}$ period beyond the end of the sample period, $T$. The generalization shows that the dynamic forecasting procedure becomes increasingly inefficient relative to the static forecasting procedure, the further the forecast is from the end of the sample period. As long as $\alpha_{2}$ is less than unity, however, increments in the variance of the dynamic forecast error will diminish with time.

The table also shows the interesting fact that the dynamic forecast error for any given period can be calculated based on the knowledge of the parameter, $\alpha_{2}$, and on the static forecast errors for that same period and prior periods; that is, the dynamic forecast error for $T+K$ is simply a weighted average of the static forecast errors, $\varepsilon_{\mathrm{T},} \varepsilon_{\mathrm{T}+1}, \ldots, \varepsilon_{\mathrm{T}+\mathrm{K}}$, with the weights determined by $\alpha_{2}$. The essential contribution of the dynamic forecasting procedure is its mique weighting scheme for current and past static forecast errors. If the investigator is interested in determining the long-run forecasting accuracy of his model, the weighting scheme of the dynamic forecasting methodology is uniquely appropriate.

It is further evident from table 2 that the weighting scheme depends crucially on the parameter $\alpha_{2}$ (the coefficient on the lagged dependent variable). Other things being equal, the researcher developing dynamic forecasts will prefer a smaller value for this parameter, because it is the mechanism by which past forecast errors are fed through the system. The smaller the coefficient on the lagged dependent variable, the less impact its value will have on subsequent forecasts. The table also shows that, if $\alpha_{2}$ exceeds unity, the dynamic forecasting framework becomes explosive: Past static forecast errors are given increasing weight as the forecast period is extended.

Finally, in terms of the question of the temporal stability of a relationship, table 2 indicates that the static and dynamic forecast errors will yield different patterns as a result of a shift in the relationship. For example, suppose a once-and-for-all intercept shift in equation (3) occurs at $T+1$, such that

(12) $\mathrm{Y}_{t}=\left(\alpha_{8}+\delta\right)+\alpha_{1} \mathrm{X}_{t}+\alpha_{2} \mathrm{Y}_{\mathrm{t}-1}+\varepsilon_{t}$

holds for all $t>T+1$. If static forecasts are developed under the erroneous assumption that equation (3) presents the correct relationship, the resulting forecast error will be $\varepsilon_{t}+\delta$ (for all $t>T+1$ ). As a result, there will be a bias in the forecast of the size, $\delta$, that will persist irrespective of the time for which the forecast is made (table 3 ).

In the case of dynamic forecasting, the path of the forecasts errors that occurs in the face of this same intercept shift is considerably different. With dynamic forecasting, the forecast will deviate from the actual level not only because the intercept shift is not built into the forecast, but also because the lagged dependent variable is inaccurately forecast for intervening periods. Since the dynamic forecasting framework is a recursive system, these latter inaccuracies will cumulate over time.

Figure 2 compares the path (i.e., the expected value) of the static and dynamic forecast errors for a once-and-for-all, $\delta$-sized intercept shift with a parameter value of $\alpha_{2}=0.7$. Although the hypothesized shift in the relationship is the same in both cases, the 


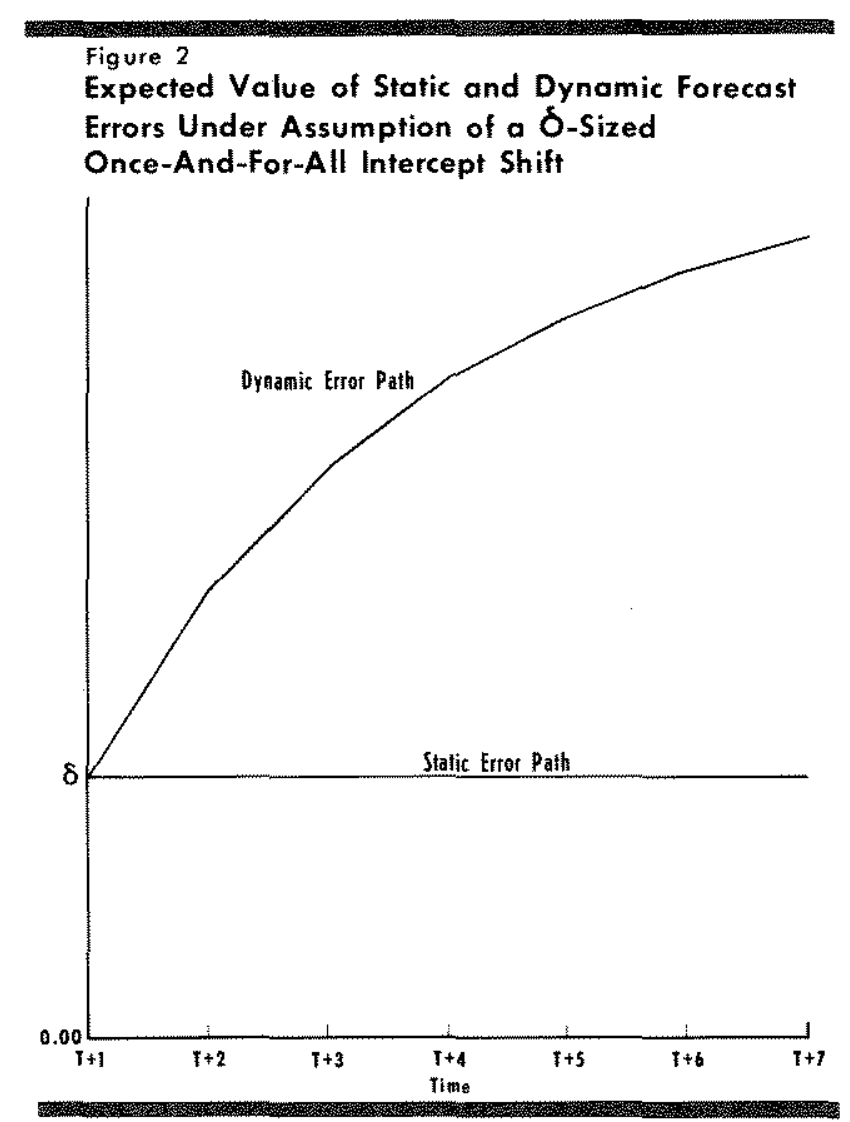

expected path of the two altemative forecast errors is quite different. Even an astute investigator could easily misjudge the once-and-for-all intercept shift in the relationship, if the only information provided is the pattern of the dynamic forecast errors. The researcher would probably perceive the shift as a continuing phenomenon, rather than a once-and-for-all occurrence. In addition, if the researcher is provided only the dyamic forecast errors, the shift in the relationship is likely to be judged larger than it actually is. In the above example, the relationship was hypothesized to have shifted up by $\delta$, but all the dynamic forecast errors after $\mathrm{T}+1$ exceed this nagnitude by ever-increasing amounts.

\section{Table 3}

\section{Static and Dynamic Forecast Errors Under the Assumption of an Intercept Shift (o)}

\begin{tabular}{|c|c|c|c|c|}
\hline Tine & $\begin{array}{l}\text { Static } \\
\text { torecast } \\
\text { error }\end{array}$ & $\begin{array}{l}\text { Bias in: } \\
\text { statle } \\
\text { forecast }\end{array}$ & $\begin{array}{l}\text { Dynamis } \\
\text { forecast } \\
\text { error }\end{array}$ & $\begin{array}{l}\text { Bus } 1 \text {, } \\
\text { forecast } \\
\text { erout }\end{array}$ \\
\hline $\mathrm{T}+1$ & $\mathrm{r}_{\mathrm{n}}+8$ & 8 & $\varepsilon_{T+1}+8$ & 8 \\
\hline $\mathrm{T}+2$ & $e_{r}+2+8$ & 8 & $\varepsilon_{t+2}+8, \alpha_{s}\left(\varepsilon_{T+1}+\delta\right)$ & $8(1+\infty)$ \\
\hline $1+3$ & $\varepsilon_{T,}+8$ & 8 &  & $8\left(1+\alpha_{1}+\alpha_{2}\right.$ \\
\hline $\mathrm{T}+\mathrm{K}$ & $\varepsilon_{1, \mathrm{~B}}+8$ & 8 & 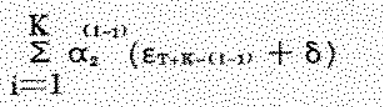 & $8\left(\sum_{1}, \alpha_{2}\right)$ \\
\hline
\end{tabular}


Table 4

Post-Sample Static Forecast of Money Demand (III/1974-IV/1979)



Calculated as actual real money stock. less the exponential of the predicted logarithm of real money balances.

\section{Static Versus Dynamic Forecasts of Money Demand}

Given this analysis, it is useful to question whether the conclusions based on dynamic forecasts of the demand for money are valid. Of specific concern are the conclusions that the money demand relationship shifted down in 1974 and that this downshift has been progressively increasing ever since.
Static out-of-sample forecasts over the period, III/ 1974 - IV $/ 1979$, were developed for the same money demand relationship given in equation (2). These forecasts, along with summary statistics, are presented in table 4.

Like the dynamic forecasts, the static money demand forecasts differ by large amounts from the actual values observed. Real money balances are consistently 
overpredicted and by fairly sizable amounts throughout the post-1974 period. The root-mean-squared-error for the static forecasts over the period III/1974 - IV/ 1979 is approximately ten times the sample period's standard error of the equation, suggesting that something in the relationship has indeed changed over the post-1974 period. $^{14}$

While the static forecast results support the conclusion that the money demand relationship has shifted, they do not corroborate other inferences drawn from dynamic forecast errors. Reliance on the dynamic forecasting technique has seriously exaggerated the magnitude of the breakdown in the relationship. For example, the II/1978 dynamic forecast of money demand overestimates real money balance by almost $\$ 27$ billion. Many studies suggest that this forecast error is an estimate of the magnitude of the "downshift" in the money demand relationship.

When the same estimated relationship is statically rather than dynamically simulated, however, a much smaller estimate of the downshift emerges. In the case of static forecasts, real money balances are projected to be "only" $\$ 13$ billion above the actual level in II/1978. The reason for the significant difference in these forecast errors is that the dynamic forecast error is simply a weighted average of current and past static forecast errors. As table 4 shows, the static forecast errors in money demand have been consistently onesided (overpredicted) since III/1974. Consequently, the dynamic forecast error for any period thereafter has always exceeded the static forecast error.

Although the dynamic forecasting procedure indicates how errors can curnulate over the long-run, it provides a poor basis for measuring the extent of the "shift" in the relationship. Again, consider the $\$ 27$ billion dynamic forecast error for II/1978. This error tells the policymaker the extent to which forecasts of real money balances would have been inaccurate if equation (2) had been used in II/1974 to project II/ 1978 money demand, assuming that he had full information about the actual course of interest rates and real income but no knowledge of the course of actual real money balances over the four-year intervening period. On the other hand, the $\$ 13$ billion static forecast error for II/1978 tells the policymaker how inaccurate his prediction of real money balances would have been if he had used the coefficients in equation (2) but had full knowledge of the I/1978 level of

14 This conclusion is further supported by a Chow test, which leads to the rejection of the hypothesis of coefficient equality over the pre-III/1974 and post-IL//1974 periods. The Fstatistic for 5,69 degrees of freedom, is 5.23 . Thus, the null hypothesis can be rejected at the 1 percent level. real money balances. Thus, over one-half of the dynamic forecast error for II/1978 is due to the error in predicting real money balances in the previous period and should not be considered part of the "shift" in the relationship.

One example of improperly using dynamic forecast errors to measure the extent of the money demand shift is provided by the work of Tinsley and Garrett. ${ }^{15}$ These authors argue that the introduction of immediately available funds (IF) in the mid-1970's was largely responsible for the downshift in money demand. To support the argument that the introduction of these financial assets have displaced a portion of conventional demand deposits, they compare the size of IF with the dynamic forecast errors for a demand deposit equation: "There is, of course, a striking similarity between the magnitude of IF ... and the size of the dynamic (emphasis added) forecast error of demand deposits. . ."16

If, as these authors argue, economic agents simply substituted IF for demand deposits in their portfolios, the dynamic forecast error should have increased at a faster rate than the growth of IF. This would occur because the dynamic forecast for periods beyond $T+1$ would differ from the actual observation by the magnitude of the shift in funds plus a weighted average of previous forecast errors for demand deposits. It is precisely this latter portion of the forecast error that many investigators ignore. Thus, rather than providing support, the similarity in magnitude between IF and the dynamic forecast errors actually casts doubt on the Tinsley-Garrett argument.

The use of the dynamic forecasting technique has also masked the pattern of the shift in the money demand relationship. As suggested at the outset, dynamic forecasts of money demand have led some researchers to conclude that there has been a continuous downshift in the relationship following II/1974, because the dynamic forecast errors have been increasing over time (figure 3). ${ }^{17}$ Obviously, the argument that this pattern of dynamic forecast errors implies a continuous shift in the relationship is invalid.

In contrast to the view of a continuous drift in the relationship, the static forecast errors suggest three

15P. A. Tinsley and Bonnie Garrett, with M. E. Friar, "The Measurement of Money Demand, SSpecial Studies Paper, No. 133 (Board of Governors of the Federal Reserve System 1978).

I0p. A. Tinsley, et. al., "The Measurement of Money Domand," p. 15.

17 For this view see Porter, et, al. "Financial Innovations and the Monetary Aggregates." For a more elementary approach, see" "Inflation and the Destruction of Monetarism," pp. 5-12. 




separate intercept shifts. ${ }^{18}$ The first shift - equal to approximately -0.03 (table 4 , colmun 4) -occurred in III/1974. There is, however, little evidence to support the notion that any further significant shifts occurred prior to IV/1975. All of the static forecast errors that occurred over the period IV/1974 - III/ 1975 are within two standard errors of the estimated equation (SEE) on either side of -0.03 .

Another discrete shift in the relationship in IV/1975 is apparent from the jump in the static forecast error from III/1975 to IV/1975. Again, while there is a slight drift in the relationship, it does not appear to change significantly over the subsequent three-year period; from IV/1975 to III/1978, the static forecast error fluctuates around -0.05 . Static forecast errors over this period are within two standard errors of the estimated equation on either side of this point. Finally, in IV $/ 1978$, another downshift is indicated by the discrete jump in the static forecast error. ${ }^{13}$ But, again,

${ }^{18}$ For support of this notion of selected shifts in the money demand relationship, see Michael $\mathrm{R}$. Darby, "The International Economy as a Source of and Restraint on United States Inflation," Working Paper No. 347 (Cambridge, Mass.: National Bureau of Economic Research, Inc., January 1980).

19Note that this latter point coincides with the introduction of nationwide ATS accounts and New York NOW accounts. the forecast error subsequently stabilizes around this higher level.

The pattern of breakdown suggested by the static estimation procedure differs greatly from that deduced from the ever-increasing dynamic forecast errors shown in figure 3 . The static forecasting procedure isolates the periods III/1974, IV/1975, and IV/1978 as the specific shift points that require further study. The analysis also suggests that, as far as short-run forecasting is concerned, the best the researcher can do in the future is to assume that any statistically significant shift in the relationship is a once-and-forall occurrence.

\section{CONGLUSTON}

This paper demonstrates that the magnitude of the recent downward shift in the money demand relationship has been exaggerated and the pattern of the precise shifts has been obscured by reliance on the dynamic forecasting procedure to evaluate the temporal stability of the money demand relationship.

The magnitude of the shift is much smaller (in fact, insignificant) if $\mathrm{MLB}$ is used in place of $\mathrm{ML}$ as the monetary aggregate measure. 
The pattern of ever-increasing dynamic forecast errors has led some investigators to conclude that money demand has been subject to a downward drift since III/1974, and, as a result, they argue that money is no longer a useful policy instrument or indicator. On the contrary, the evidence in this paper supports the notion of discrete once-and-for-all shifts in the relationship, and isolates the periods of late III/1974, IV/1975, and IV/1978 as specific periods of these shifts.

By rejecting the notion of a constantly shifting money demand relationship, this paper reaffirms the usefulness of money as a policy instrument. By using the conventional money demand equation considered here, a policymaker, unaware of the financial innovations occurring over the recent period, would have made only three significant errors in forecasting the growth rate of real money balances. Consequently, only on these three separate occasions would the linkage between money and prices have been other than expected.
Finally, although this paper has presented longrange (dynamic) forecasts of money demand which are in serious error, this evidence should not be interpreted as highly critical of a long-range policy of money control, such as Friedman's X-percent rule. The period considered in this paper, III/1974 IV/1979, was one of ever-accelerating monetary growth, which resulted in a higher rate of inflation, as well as higher interest rates. These high interest rates, in turn, have led to financial innovations (e.g., ATS accounts, NOW accounts, and money market mutual funds) designed to circumvent Federal Reserve regulations (primarily Regulation $Q$ interest rate ceilings). To the extent that these financial innovations have been responsible for the shifts in money demand, the ultimate precursor of the shifts has been the excessive growth of money over this period. In other words, it is legitimate to question whether money demand would have been subject to the few shifts experienced had monetary growth not accelerated over the past decade.

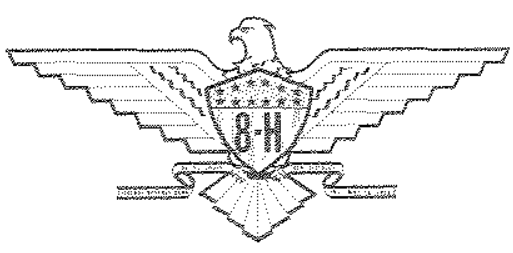

